\title{
Trend of Neonatal Mortality in Nigeria from 1990 to 2017 using Time Series Analysis
}

\author{
${ }^{1}$ USMAN, A; ${ }^{2}$ SULAIMAN, MA; ${ }^{3}$ ABUBAKAR, I \\ ${ }^{1,2}$ Department of Statistics, School of Physical Sciences, Federal University of Technology, Minna, Nigeria \\ ${ }^{3}$ School of Applied and Natural Science, Microbiology Unit, Niger State Polytechnic, Zungeru, Niger State, Nigeria \\ *Corresponding Author Email: abu.usman@futminna.edu.ng
}

\begin{abstract}
The study examined the incidence of the rate of Neonatal Mortality in Nigeria. The incidence tested with use of Time Series Analysis (ARIMA). The trend plot of the incidence shows that there has been steady decrease in the incidence rate over the years. The series was stationarity using the Augmented Dickey-Fuller (ADF) Test, the result found to be stationary. The Correlogram of the incidence also supports the stationarity of the series at $1 \%$ level of significance. The model that best describes the incidence was tested using the Box-Jenkins four step procedures, which involve identification, explanation, diagnostic and forecasting. $\operatorname{ARMA}(1,1)$, and $\operatorname{ARIMA}(1,1,1)$ models were tested, and ARIMA $(1,1,1)$ model happens to be the best model that best fits the series. The time series analysis shows that neonatal mortality rate has reduced by $17.8 \%$ from $\quad 51.7 \%$ in the year 1990 to $33.9 \%$ in the year 2017 .
\end{abstract}

DOI: https://dx.doi.org/10.4314/jasem.v23i5.15

Copyright: Copyright $\left({ }^{\circ} 2019\right.$ Usman et al. This is an open access article distributed under the Creative Commons Attribution License (CCL), which permits unrestricted use, distribution, and reproduction in any medium, provided the original work is properly cited.

Dates: Received: 10 December 2018; Revised: 21 May 2019; Accepted 23 May 2019

Keywords: Auto regression, Moving average, Mortality, Stationarity, Correlogram

Neonatal mortality is a significant public health problem worldwide, and accounts for more than $60 \%$ of newborn deaths before their first birthday [UNICEF 2008], neonatal mortality rate is the number of neonates dying before reaching 28 days of age, per 1,000 live births in a given year. Previous studies have shown that about half of infant deaths occur in the neonatal period. Knowledge of the determinants of neonatal mortality are essential for the design of intervention programs that will enhance neonatal survival. Therefore, this study was conducted to investigate the trends and factors associated with neonatal mortality in Nigeria from 1990 to 2017. The neonatal mortality can be prevented or reduced through the following measures, Policy $\square$ National Health Bill implementation will strengthen primary care and make funds available for implementation of Integrated Maternal Newborn and Child Health (IMNCH) Strategies, expansion and provision of Neonatal Intensive Care Unit (NICU) services and equipment in the tertiary. Centers, increase in training on ENC and Neonatal resuscitation in all hospitals, adequate staffing - doctors, nurses, facilitators, training and re $\square$ training of staff., NGOs organizations and other bodies working on maternal and Newborn survival.

\section{MATERIALS AND METHODS}

Method of Data Analysis: The methods of data analysis that will be employed in this study is the Time Series Analysis using Autoregressive Integrated Moving Average (ARIMA). The statistical softwares that will be used in this study are; Minitab and Gretl.

Autoregressive (AR) Model: $\mathrm{n}$ statistics and sigma process, an autoregressive (AR) model is a type of random process which is often used to model and predict various types of natural phenomena. The autoregressive model is one of a group of linear prediction formulae that attempt to predict an output of a system based on the previous outputs. The $\mathrm{AR}_{(\mathrm{p})}$ indicates an autoregressive model of the order $\mathrm{p}$. the $\mathrm{AR}_{(\mathrm{p})}$ model is defined as:

$$
Y_{t}=\beta_{0}+\beta_{1} X_{t-1}+\beta_{2} X_{t-2}+\beta_{3} X_{t-3}+\cdots+\beta_{p} X_{t-p}+\varepsilon_{t}
$$

Where $\beta_{i} X_{t-i}$ are the parameters of the model, $\beta_{0}$ is a constant (often omitted for simplicity) and $\varepsilon_{\mathrm{t}}$ is a white noise.
Some constraints are necessary on the values of the parameters of this model in order that the model remain wide sense stationary. For example, processes in the AR(i) model with $\left|p_{i}\right| z \mid$ are not stationary. More generally, for an $\mathrm{AR}(\mathrm{p})$ model to be wide sense 
stationary, the root of the polynomial must lie within the unit circle i.e. each root 2 , must satisfy $2,1<1$

An AR(i) process is given by: $Y_{t}=\beta_{0}+\varepsilon_{t}$

Where $\varepsilon_{\mathrm{t}}$ is white noise process with zero mean and variance 1 i.e. $E\left(Y_{t}\right)=\beta_{0}$

Moving Average (MA) Process: In statistics, a moving average is a calculation to analyze data points by creating series of averages of different of the full data set. A moving average is commonly used with time series data to smooth out short-term fluctuations and high-light longer-term trends or cycles.
Mathematically, moving average can be expressed as:

$$
M \cdot A=\sum_{i}^{n} \frac{X i}{n} \quad \mathrm{i}=1,2,3, \ldots, \mathrm{n}
$$

Where $\mathrm{X}_{\mathrm{i}}$ is the individual observations and $\mathrm{n}=$ the number of moving average.

In time series analysis, the moving average model is a common approach for modeling univariate time series. The moving average model specifies that the output variable depends linearly on the current and past values of a stochastic term. The moving average process of order q denoted by:

$$
Y_{t}=\varepsilon_{t}-\theta_{1} \varepsilon_{t-1}-\theta_{2} \varepsilon_{t-2}-\theta_{3} \varepsilon_{t-3}-\cdots-\theta_{q} \varepsilon_{t-q}
$$

Autoregressive Integrated Moving Average Process (ARIMA): A time series process formed from the combination of AR and MA called Autoregressive Moving average process of order $p, q$ is called an ARIMA process ( $s$ ) if it contains (p) AR terminals, (d) differencing and (q) MA terminals. This is a fact that a stationary time series process may often be defined on ARIMA process which involves fewer parameters than AR and MA. Stationary $X_{t}$ satisfies ARIMA process of order (p, d, q) abbreviated as ARIMA (p, d, q) if:

$$
Y_{t}=\beta_{0}+\beta_{1} X_{t-1}+\beta_{2} X_{t-2}+\beta_{3} X_{t-3}+\cdots+\beta_{p} X_{t-p}+\varepsilon_{t}-\theta_{1} \varepsilon_{t-1}-\theta_{2} \varepsilon_{t-2}-\theta_{3} \varepsilon_{t-3}-\cdots-\theta_{q} \varepsilon_{t-q}
$$

Unit Root Test: In statistics, a unit root test employed in testing whether or not a time series variable is stationary or not and possess a unit root. With the null hypothesis stating that there is presence of a unit root (not stationary) while the alternative hypothesis states that there is no presence of a unit root (stationary). The unit test was derived in 1979 by Dickey and fuller to test the presence of a unit root vs stationary process. There are several methods through which we can check the stationarity (or unit toot) in the time series setting. It starts with simple autoregressive scheme, which is as follows:

$$
Y_{t}=\alpha+\rho y_{t-1}+\varepsilon_{t}
$$

Where $\rho$ is an autoregressive (AR) coefficient. If $\rho=$ 1 , the series can be said to have unit root and is not stationary. That indicates that the mean and variance are not constant and violates the normal requirement of time series modeling.

There are several procedures that has been developed to test for the stationarity of a series. The most popular ones are Augmented Dickey-Fuller (ADF), PhillipsPerron (PP) test and Kwiatkowski- Philips- SchmidtShin (KPSS) test.

Autocorrelation Function: Suppose we have a random variable say $X$ and $Y$ and then a pair of observation $\left(X_{1}, X_{2}, \ldots, X_{n}\right),\left(Y_{1}, Y_{2}, \ldots, Y_{n}\right)$ in a classical statistic. If there is measure of independent of $\mathrm{Y}$ on $\mathrm{X}, \mathrm{P}_{\mathrm{h}}$ measures correlation between successive observations, it is called a condition between $X_{t}$ and $\mathrm{X}_{\mathrm{t}+1}$ and is given by

$$
\mathrm{P}_{h}=\frac{\operatorname{cov}\left(X_{t}-X_{t+1}\right)}{\sqrt{\operatorname{var}\left(X_{t}\right) \cdot \operatorname{var}\left(X_{t+1}\right)}}
$$

With the following properties $(i)-1 \leq P_{h} \leq$ 1 (ii) $\operatorname{Var}\left(X_{i}\right) ; \operatorname{Var}\left(X_{t+1}\right)$ should not be negative and $t$ is stationary.

Partial Autocorrelation Function: The autocorrelation used to measure the correlation between the current observation of time series and observation $\mathrm{k}$ period ago after controlling for observation at intermediate lag i.e. for all lags less than $\mathrm{k}$.

PAC $(k)=$ AC after controlling the effects of $\left(Y_{t}\right.$, ....... $\left.\mathrm{Y}_{\mathrm{t}-\mathrm{k}+1}\right),\left(\mathrm{Y}_{\mathrm{t}-\mathrm{k}}\right)$. At lag (1),

the $(1)=$ PAC (1) always. At lag (2), the AC (2) $=\left(\rho_{0}\right.$ $\left.-\rho_{12}\right) /\left(1-\rho_{12}\right)$ for lag $(3)$ and lags greater than 3 , the formula is more complex. PAC (k) can be obtain as the coefficient of $\mathrm{Y}_{\mathrm{t}-\mathrm{k}}$ in the regression.

$\mathrm{Y}_{\mathrm{t}}=0+1 \mathrm{Y}_{\mathrm{t}-1}+2 \mathrm{Y}_{\mathrm{t}-2}+\cdots+\mathrm{k}-1 \mathrm{Y}_{\mathrm{t}}$

This implies that $\operatorname{PAC}(\mathrm{k})=\mathrm{k}$.

The PAC is also used to tell the maximum order of an auto regression process and test of a Moving Average Process.

For $\mathrm{AR}_{(\mathrm{p})}$ models, $\mathrm{PAC}_{(\mathrm{p}+\mathrm{s})}=0, \mathrm{~S} \geq 1$ 
For MA ${ }_{(q)}$, the PAC will be decreasing geometrically.

\section{RESULTS AND DISCUSSIONS}

The time plot in Figure 1 shows that Neonatal Mortality Rate in Nigeria exhibits a curvilinear trend pattern.

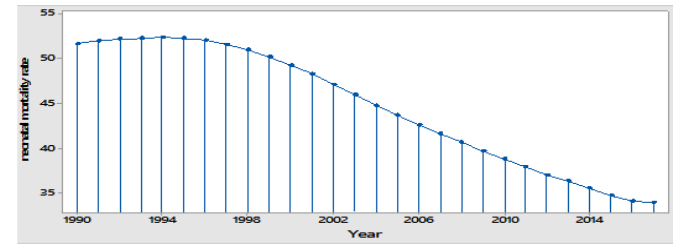

Fig 1 Time series plot of neonatal mortality rate in Nigeria from 1990 to 2017

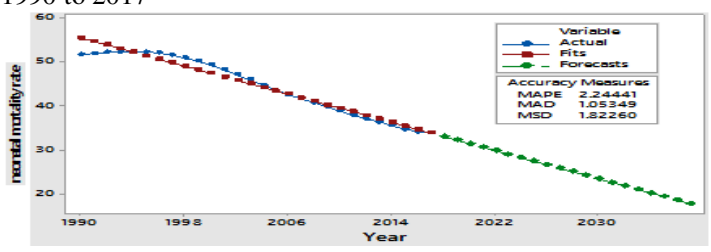

Fig 2 Trend analysis of neonatal mortality rate in Nigeria from 1990 to 2037

From Figure 2, the mean absolute percentage error $(\mathrm{MAPE})=2.24$ which implies that the forecast of the data is off by $2 \%$ which means that percentage of error for the series is $2 \%$. Likewise, the mean absolute deviation $(\mathrm{MAD})=1.05$ which indicates that the series of good fit, as the lower the MAD, the better the fit of the series.

Stationarity Test: A stationarity test employed in testing whether or not a time series variable possesses a unit root. The hypothesis for this work is

$\mathrm{H}_{0}$ : There is a unit root for the series.

$\mathrm{H}_{1}$ : There is no unit root for the series. The series is stationary.

Decision rule: if p-value is less than the significance level alpha $=0.01$, we reject $\mathrm{H}_{0}$ and conclude $\mathrm{H}_{1}$. We do not reject $\mathrm{H}_{0}$ if otherwise. Unit-root null hypothesis: $\mathrm{a}=1$

Table 1 Augmented Dickey-Fuller Test Neonatal Mortality in Nigeria

\begin{tabular}{llll}
\hline Variable & Tau_c(1) & P-value & $\mathbf{1}^{\text {st }}$ order ACF coeff for e \\
\hline Neonatal Mortality Rate & -3.79944 & 0.002927 & -0.216 \\
\hline
\end{tabular}

$\mathrm{a}$ is the differenced order; Since the computed P-value $=0.0029$ is greater than the significance level $\alpha=0.01$, we reject $\mathrm{H}_{0}$ and conclude that the series is stationary.

Table 2 ARMA Model $(1,1)$ : Neonatal Mortality Rate; Final Estimates of Parameters

\begin{tabular}{lllllllc}
\hline Type & Coef & SE Coef & T-value & P-value & DF & SS & MS \\
\hline AR 1 & 1.0349 & 0.0192 & 53.96 & 0.000 & 25 & 2.89242 & 0.115701 \\
MA 1 & -0.9460 & 0.1037 & -9.12 & 0.000 & & & \\
Constant & -1.80501 & -0.18080 & 9.98 & 0.000 & & & \\
Mean & 51.729 & 5.182 & & & & & \\
\hline
\end{tabular}

From Table 2, the p-value of both the AR and MA = 0.000 which is less than the level of significance $\alpha=$
0.01 , we reject $\mathrm{H}_{0}$ and conclude that the series are serially correlated. Hence the series is not fit.

\begin{tabular}{lllll} 
Table 3 Modified Box-Pierce (Ljung-Box) & Chi-Square Statistic \\
\hline Lag & $\mathbf{1 2}$ & $\mathbf{2 4}$ & $\mathbf{3 6}$ & $\mathbf{4 8}$ \\
\hline Chi-Square $\left(\chi^{\mathbf{2}}\right)$ & 54.8 & 101.10 & $*$ & $*$ \\
DF & 9 & 21 & $*$ & $*$ \\
P-value & 0.000 & 0.000 & $*$ & $*$ \\
\hline
\end{tabular}

From Table 3.3, the Modified Box-Pierce (Ljung-Box) Chi-Square Statistic, the P-value at lag 12 and lag 24 $=0.000$ and 0.000 which are less than the significance level $\alpha=0.01$ we reject $\mathrm{H}_{0}$ and conclude that the series are correlated i.e. insignificant.

Table 4 ARIMA Model $(1,1,1)$ : Neonatal Mortality Rate Final Estimates of Parameters; Differencing: 1 regular difference Number of

\begin{tabular}{llllllll}
\multicolumn{7}{c}{ observations: } & Original series 28, after differencing 27: Number of observations: 28 \\
\hline Type & Coef & SE Coef & T-value & P-value & DF & SS & MS \\
\hline AR 1 & 0.9778 & 0.0748 & 13.08 & 0.000 & 24 & 0.543012 & 0.022626 \\
MA 1 & -0.2272 & 0.2237 & -1.02 & 0.320 & & & \\
Constant & -0.00213 & 0.05480 & -0.04 & 0.969 & & & \\
\hline
\end{tabular}

From Table 4, it was discovered that the best model fit to model the neonatal mortality rate is $\operatorname{ARIMA}(1,1$,
1) because the P-value is greater than the level of significance $\alpha=0.01$ at MA (1). Since the $\mathrm{p}$-value $=$ 
0.320 is greater than the significance level $\alpha=0.01$, we fail to reject $\mathrm{H}_{0}$ and conclude that the series is uncorrelated. i.e. it is a very good model. Also studying the MS, it is the model with the smallest MS and hence the best model.

\begin{tabular}{cllll} 
Table 5 Modified Box-Pierce (Ljung-Box) & Chi-Square Statistic \\
\hline Lag & $\mathbf{1 2}$ & $\mathbf{2 4}$ & $\mathbf{3 6}$ & $\mathbf{4 8}$ \\
\hline Chi-Square $\left(\chi^{2}\right)$ & 12.8 & 34.1 & $*$ & $*$ \\
DF & 9 & 21 & $*$ & $*$ \\
P-value & 0.174 & 0.035 & $*$ & $*$ \\
\hline
\end{tabular}

From Table 5, the Modified Box-Pierce (Ljung-Box) Chi-Square Statistic, the P-value at lag 12 and lag $24=$ 0.174 and 0.035 which are greater than the significance level $\alpha=0.01$ which also confirms that the series are uncorrelated i.e. significant.

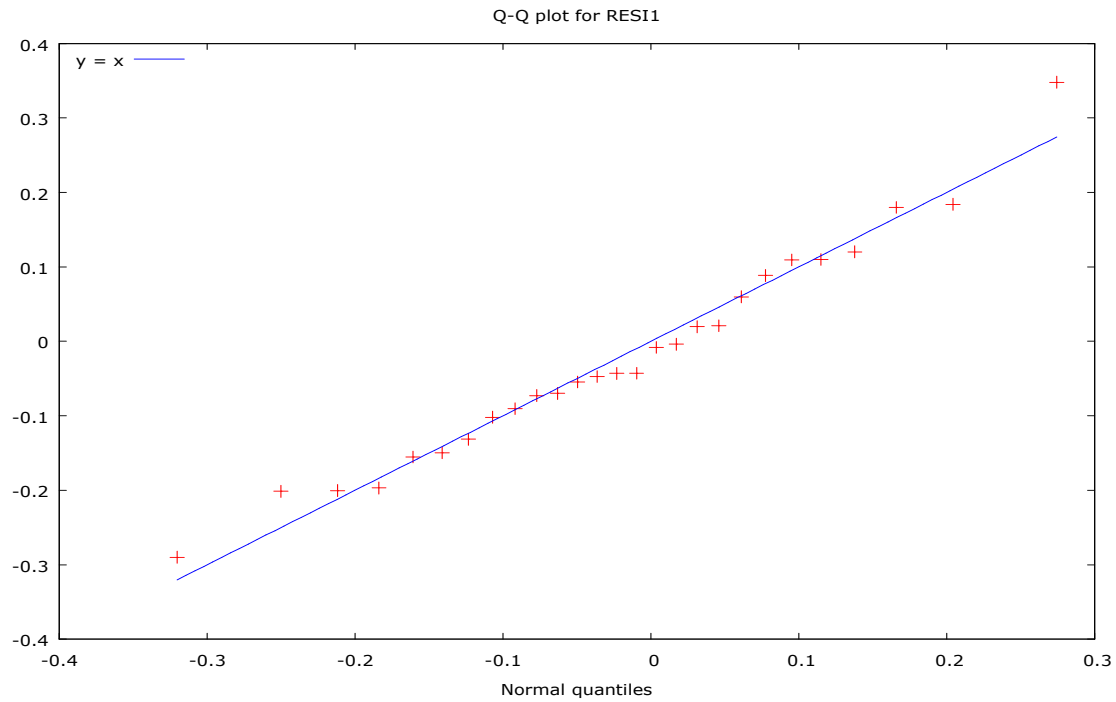

Fig 3 Quantile Plot for the Model Residuals of Neonatal Mortality Rate

The Quantile plot of neonatal mortality rate appears to exhibit a straight line, which also confirms the normality of the residuals.

Forecasting: A forecast made to predict the future occurrence of neonatal mortality in Nigeria. So that it can serve as a help to federal government and to the health sector, for control measures and awareness. A forecast of 20 years was made using a base year of 2017 between 2018 to 2037.

Table 6: Forecast Section for the Occurrence of Neonatal Mortality in Nigeria from 2018 to 2037

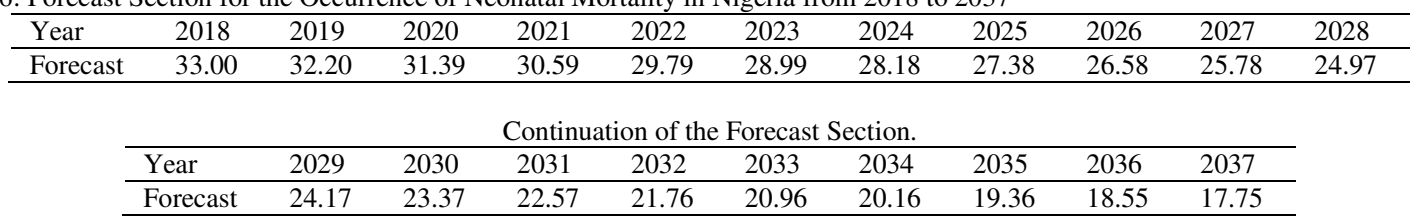

The forecast shows that there will be a consistent decline in neonatal mortality rate in Nigeria in years to come. It is expected that neonatal mortality rate will in the next 20 years drop to $17.75 \%$ as against the present $33.9 \%$, which means a decline of about $16 \%$.

Conclusion: This study critically accessed the incidence of Neonatal Mortality in Nigeria between 1990 to 2017, the time plot of the incidence of neonatal mortality exhibits a downward movement which shows that neonatal mortality is been conquered gradually, but over the period of this study, there has been a significant decrease in the incidence of neonatal mortality. Nigeria is gradually winning the war against child mortality, especially war against neonatal mortality. More measures needs be put in place to further help in fighting neonatal mortality.

\section{REFERENCES}

Ahonsi BA. (1995) Age variations in the proximate determinants of child mortality in south-west Nigeria. J Biosoc. Sci. Jan; 27(1):19-30. 
Caldwell, J. C. (2009). Education as a Factor in Mortality Decline: An Examination of Nigerian Data. Population Studies, 33 (3), 395- 414.

http://www.ncbi.nlm.nih.gov/pmc/articles/PMC4395 970/

Hurvich et al (1989): "Regression and Time Series Model Selection in Small Samples", Biometrika 76: 297-307

Inter-agency Group for Child Mortality Estimation (IGME): Levels and Trends in child mortality. (2012):

http://www.who.int/maternal_child_adolescent/docu ments/levels_trends_child_mortality_2012.pdf

Jinadu, M.K., Olusi, S.O., Agun, J.I; A.K. Fabiyi (1991) and NBS (2011): "Childhood Diarrhea in Rural Nigeria: Studies on Prevalence, Mortality and Socio-Environmental Factors" Journal of Diarrhea Diseases Research. 9 (4): 323-327

Osonwa, O.K., Iyam, M.A., \& Osonwa, R.H., (2012). Under-Five Mortality in Nigeria: Perception and Attitudes of the IKWERRES in Rivers State towards the Existence of "OGBA - NJE". $J$. Sociological Res... 3, (2): 587-598
Pandey, M. J. (2009). Maternal Health and Child Mortality in Rural India. ASARC Working Paper 12. Institute of Economic Growth, Delhi, India.

Uddin, M., Hossain, M., \& Ullah M.O., (2009). Child Mortality in a Developing Country: A Statistical Analysis. Journal of Applied Quantitative Method, 4. (3), 270-283

United Nations Children's Fund (2010). Levels and Trends in Child Mortality - Report 2010. Estimates Developed by the United Nations InterAgency Group for Child Mortality Estimation. United Nations Children's Fund. 2010

United Nations Inter-Agency Group for Child Mortality Estimation (2013). Levels \& Trends in Child Mortality - Report 2013. UN Inter-Agency Group for Child Mortality Estimation. United Nations, New 2013. http://www.mamaye.org.ng/evidence/levels$\underline{\text { trendschild-mortality-report-2013 }}$

Uthman O. A. (2008): Effect of low birth weight on infant mortality: analysis using Weibull Hazard Model. The internet Journal of Epidemiology 6. (1), 8 